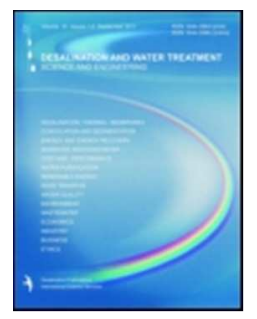

\title{
REVERSIBILITY OF FOULING ON ULTRAFILTRATION MEMBRANE BY BACKWASHING AND CHEMICAL CLEANING: DIFFERENCES IN ORGANIC FRACTIONS BEHAVIOUR
}

\begin{tabular}{|r|l|}
\hline Journal: & Desalination and Water Treatment \\
\hline Manuscript ID: & Draft \\
\hline Manuscript Type: & Original Paper \\
\hline Date Submitted by the Author: & n/a \\
\hline Complete List of Authors: & $\begin{array}{l}\text { Ferrer, Olga; CETaqua, } \\
\text { Lefèvre, Benoît; CETaqua, } \\
\text { Prats, Guillem; CETaqua, } \\
\text { Bernat, Xavier; CETaqua, } \\
\text { Gibert, Oriol; Universitat Politècnica de Catalunya, Chemical Engineering } \\
\text { Paraira, Miquel; Aigües de Barcelona, }\end{array}$ \\
\hline Keywords: & $\begin{array}{l}\text { backwashing, fouling reversibility, organic fractions, surface water } \\
\text { treatment, ultrafiltration }\end{array}$ \\
\hline
\end{tabular}

SCHOLARONE ${ }^{\text {'t }}$

Manuscripts 


\title{
REVERSIBILITY OF FOULING ON ULTRAFILTRATION MEMBRANE
}

BY BACKWASHING AND CHEMICAL CLEANING: DIFFERENCES IN ORGANIC FRACTIONS BEHAVIOUR

\author{
Olga Ferrer ${ }^{\mathrm{a}}$, Benoît Lefèvre ${ }^{\mathrm{a}}$, Guillem Prats ${ }^{\mathrm{a}}$, Xavier Bernat ${ }^{\mathrm{a}}$, \\ Oriol Gibert $^{\mathrm{a}, \mathrm{b}, *}$, Miquel Paraira ${ }^{\mathrm{c}}$
}

\author{
${ }^{a}$ CETaqua, Water Technology Center, Ctra. d'Esplugues 75, 08940 Cornellà de Llobregat, \\ Spain \\ ${ }^{\mathrm{b}}$ Departament d'Enginyeria Química, ETSEIB, Universitat Politècnica de Catalunya, Av. \\ Diagonal 647, 08028 Barcelona, Spain \\ ${ }^{c}$ Aigües de Barcelona S.A., General Batet 5-7, 08028 Barcelona, Spain
}

Corresponding author: Oriol Gibert, email: oriol.gibert@upc.edu, Tel: +34 934011818

\begin{abstract}
Membrane fouling is an inherent phenomenon in UF membrane processes, making it necessary to periodically perform backwashes (BW) and chemical "cleanings in place" (CIP) to restore the initial permeability of the membrane. The objective of this study was 1) to explore systematically the effect of distinct BW-related variables (BW transmembrane pressure, duration, frequency, composition) on the reversibility of UF membrane fouling and on the permeate quality (in terms of total organic carbon, turbidity and UV absorbance) over successive filtration/BW cycles; and 2) to identify which organic fractions were most removed by the membrane and, of these, which were most detached after BW, alkaline and oxidant CIP and acid CIP episodes. For this purpose, a bench-scale outside-in hollow fibre module operated under dead-end filtration mode at constant transmembrane pressure and treating settled water from a drinking water treatment plant was employed. Dissolved organic carbon fractionation was performed by high performance size exclusion chromatography (HPSEC). Results showed that in general the more intensive a BW was (in terms of high transmembrane pressure, shortened frequency and prolonged duration) the more effective it was in removing fouling from the membrane. Concerning the composition of the water used for the BW, the addition of $\mathrm{NaClO}$ led to maximum fouling reversibility, closely followed by the combination of $\mathrm{NaOH}+\mathrm{NaClO}$, while citric acid and $\mathrm{NaOH}$ contributed little compared to water alone. However, results also showed that irreversible fouling was never completely avoided whatever the BW regime applied, leading to a gradual increase of the total resistance over time. Larger
\end{abstract}


differences in the behaviour of the different organic fractions were observed. UF membrane preferentially retained the heaviest fraction of biopolymers (BP), while the intermediate fraction of humic substances (HS) was removed at a lower percentage and the lighter fractions seemed to entirely pass through the UF membrane. The successive application of BW and CIPs resulted in the detachment from the membrane of a significant percentage of the retained BP, whereas only a modest percentage of the retained HS.

Keywords: backwashing; fouling reversibility; organic fractions; surface water treatment; ultrafiltration

\section{INTRODUCTION}

Application of pressure-driven membrane processes as microfiltration (MF) and ultrafiltration (UF) has expanded in recent years as an alternative technology for wastewater treatment and drinking water production. This expansion is due to the fact that UF has proved to be an effective physical barrier to particles, colloids, bacteria and certain viruses that are larger than the UF membrane pores and, hence, are retained by size-exclusion mechanisms, among others. Furthermore, UF provides extra advantages over conventional treatments such as small footprint, low energy consumption, limited chemical dosing, capability of coping with wide fluctuations in feed quality and delivering permeate of relatively constant quality, and reduced scale-up risks [1-5].

The retained particles accumulated on the feed side of the membrane (and within the membrane pores), however, give rise to the major drawback of UF systems: fouling formation. Fouling leads to additional hydraulic resistance to permeate flow, increase of the energy consumption of the process, lowering of the productivity, worsening of the product quality and eventually premature replacement of membranes [2,4,6-8].

In order to remove fouling, UF membranes are periodically subjected to physical cleaning such as backwashing (BW). BW is performed by reversing the direction of flow through the membrane to dislodge and remove foulants from it and restore the initial permeability [6,8-10]. Fouling removed by a hydraulic cleaning such as BW is referred to as "physically reversible fouling", in opposition to the "irreversible fouling" made of substances strongly adhered on or within the membrane and not flushed out by any physical cleaning procedure. It is this irreversible fouling that leads to a long-term increase of the resistance (with the subsequent increase of the operational costs) and to a progressive deterioration of the membrane. 
The operation of a UF membrane consists, then, of a succession of cycles each comprising a filtration step (in which membrane resistance gradually increases due to fouling) and a BW step (in which membrane resistance is lowered as foulants are removed from the membrane). Figure 1 schematically represents the evolution of the total membrane resistance during its operation, showing all its components, i.e. resistance of clean membrane $\left(\mathrm{R}_{\mathrm{m}}\right)$, resistance due to the reversible fouling $\left(\mathrm{R}_{\text {rev }}\right)$ and resistance due to the irreversible fouling $\left(\mathrm{R}_{\text {irrev }}\right)$.

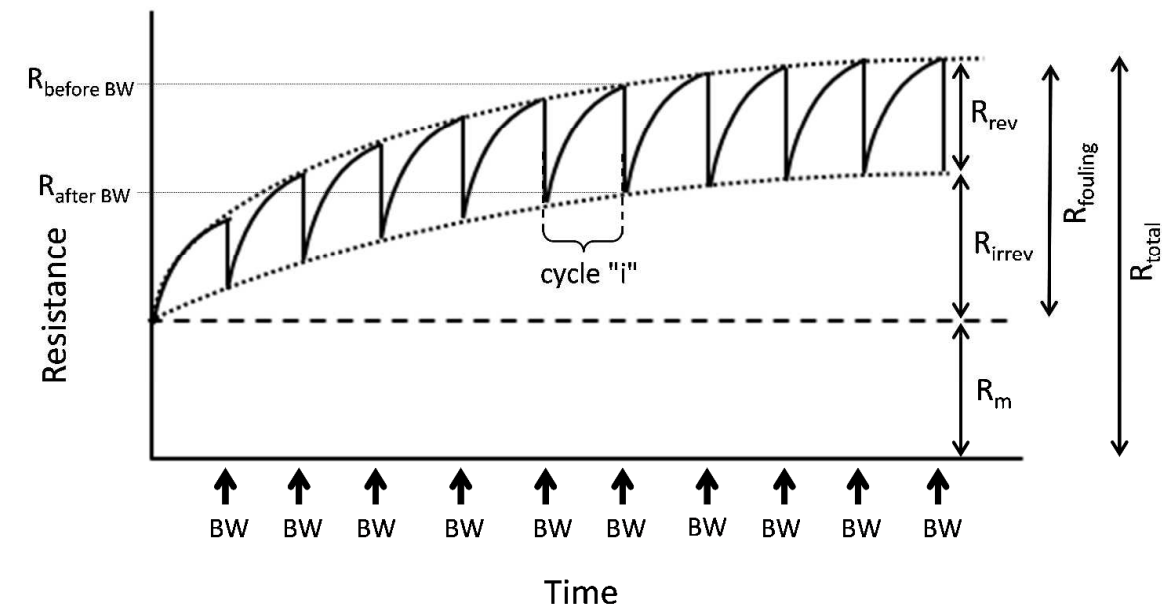

Figure 1: Qualitative representation of the evolution of membrane resistance over a succession of filtration and backwashing (BW) cycles.

The removal of the irreversible fouling can be partially achieved only through aggressive chemical cleaning ("cleaning in place" (CIP)), which is usually burdensome and requires the shutdown of the unit being cleaned for several hours. Chemical cleaning causes both a reduction of the overall production plant capacity and a deterioration of the membranes, wherefore it should be minimised wherever possible [3,11]. A strategy that helps minimise chemical cleaning is the addition of chemical cleaners into the water used for BW, giving rise to the so-called "chemically-enhanced backwash" (CEB) [12]. This cleaning operation does not require an extended shutdown, since it is conducted on line, and the chemicals' concentration and/or their nature tend to be less aggressive compared to the CIP ones. As a consequence, typically CEBs are less effective than CIPs.

The extent and reversibility of membrane fouling is largely dependent on multiple variables such as membrane characteristics, feed water properties, filtration conditions, module configuration, BW regime... making the control of membrane fouling a complex phenomenon. Among these, the effect of feed water composition and membrane operating conditions have been most researched $[8,13-15]$, while less studies have dealt with the effect that $\mathrm{BW}$ variables 
(duration, frequency...) or different organic components of the dissolved organic matter (DOM) exhert on UF membrane fouling.

Comparison of results from studies on BW variables is, moreover, not entirely reliable and needs to be treated with caution for several reasons. First, these studies treat different types of water: wastewater $[2,5,6,11,12,16]$, seawater $[1,17,18]$ and surface water $[3,10]$, each with different fouling behaviour potential under a given BW regime. For instance, it has been reported that a high salt concentration in the seawater might influence the interaction forces between membrane and foulants [1]. Second, the configuration of UF modules in these st8] udies is very variable: flat-sheet [10], spiral wound [17], pressurized (inside-out) [5,6,12,18] and submerged (outside-in) [1,10] hollow fibre membrane systems, also affecting the propensity to fouling $[1,16,19]$. Furthermore, most of them are focused on the evolution of the membrane resistance and fouling rates $[2,3,5,6,16]$ and only a few quantify the reversible and irreversible fouling after each backwash cycle [1]. Within this context, more research is still needed on quantitatively determining the effect of BW-related variables on the reversibility of fouling on UF membranes for all scenarios and, in particular, for the outside-in hollow fibre UF for surface water.

Fouling by DOM components or fractions is also gaining increasing attention of researchers. Indeed, it is acknowledged that different constituents of DOM do not necessarily foul UF membranes on the same way or degree [20-22]. Characterizing such DOM fractions is thus essential for a better understanding of which constituents contribute most in the fouling of a UF membrane. Among the methods developed to characterize DOM, high performance size exclusion chromatography (HPSEC) (whereby DOC fractions are separated according to their hydrodynamic size) has gained much attention as a powerful method for quantitative and qualitative characterization of DOC [23].

The objective of this study was 1) to explore systematically the effect of distinct BWrelated variables on the reversibility of UF membrane fouling and on the permeate quality over successive filtration/BW cycles in the treatment of surface water; and 2) to identify which organic fractions were best removed after backwashing (BW) and cleaning-in-place (CIP) episodes. For this purpose, a bench-scale outside-in hollow fibre module operated under deadend filtration mode at constant transmembrane pressure (TMP) was employed. The variables of study comprised BW TMP, duration and frequency as well as composition of CEBs. Permeate quality was monitored in terms of total organic carbon (TOC), turbidity and UV absorbance $\left(\mathrm{UV}_{254}\right)$. For the second objective, DOC fractionation was performed by HPSEC. 


\section{METHODS}

\subsection{Feed water characteristics}

The feed water to be filtered by the UF module was decanted water from the settling basin of the drinking water treatment plant in Sant Joan Despí (Barcelona, Spain). The average composition of this water during the course of the study is given in Table 1.

Table 1: Average feed water quality

\begin{tabular}{lc} 
Parameter & Concentration \\
\hline $\mathrm{pH}$ & 7.6 \\
Conductivity $(\mu \mathrm{S} / \mathrm{cm})$ & 1490 \\
Turbidity $(\mathrm{NTU})$ & 1.76 \\
$\mathrm{Abs}_{254}(\mathrm{abs} / \mathrm{m})$ & 0.080 \\
$\mathrm{TOC}(\mathrm{mg} / \mathrm{L})$ & 4.1 \\
$\mathrm{Al}(\mu \mathrm{g} / \mathrm{L})$ & 364 \\
$\mathrm{Fe}(\mu \mathrm{g} / \mathrm{L})$ & 23 \\
$\mathrm{P}(\mu \mathrm{g} / \mathrm{L})$ & 43 \\
\hline
\end{tabular}

\subsection{UF device and membrane characteristics}

All experiments conducted in this study were carried out employing a bench-scale outside-in hollow fibre module (Polymem UF0808M3) operated under dead-end filtration mode at constant TMP. The main characteristics of the UF module provided by the manufacturer are shown in Table 2. 
Table 2: Characteristics of the UF membrane module provided by the manufacturer.

\begin{tabular}{ll}
\hline Manufacturer & Polymem \\
Membrane type & UF0808M3 \\
Filtration mode & Out-in \\
Membrane material & Polysulfone \\
Potting material & Polyurethane \\
Vessel material & U-PVC \\
Fibre diameter $(\mathrm{mm})$ & 1.4 \\
Surface area $\left(\mathrm{m}^{2}\right)$ & 0.01 \\
Module external diameter $(\mathrm{mm})$ & 20 \\
Module length $(\mathrm{mm})$ & 200 \\
Nominal MWCO $(\mathrm{Da})$ & 300000 \\
Nominal Pore size $(\mu \mathrm{m})$ & 0.08 \\
Maximum feeding pressure $($ bar $)$ & 3.0 \\
Maximum TMP $($ bar $)$ & 1.5 \\
Maximum TMP during backwash $($ bar $)$ & 2.0 \\
Maximum temperature $\left({ }^{\circ} \mathrm{C}\right)$ & 35 \\
pH range & $2-12$ \\
\hline
\end{tabular}

The decanted feed water was directed to the UF module by means of a centrifugal pump (IML S.A.U., Model MS100M). Valves in the system were opened and closed such that the direction of flow was out-in during the filtration step and reversed to in-out during the BW step. During filtration the feed solution passed through the UF membrane and permeate was collected for flux measurements and chemical analysis. TMP was measured by a pressure gauge (Keller Group, model Leo 3). During BW, UF permeate was pumped using a peristaltic pump (Heidolph, model Pump drive PD5001) and the backwash stream discharged into a separate tank. A schematic diagram of the experimental set-up is shown in Figure 2.

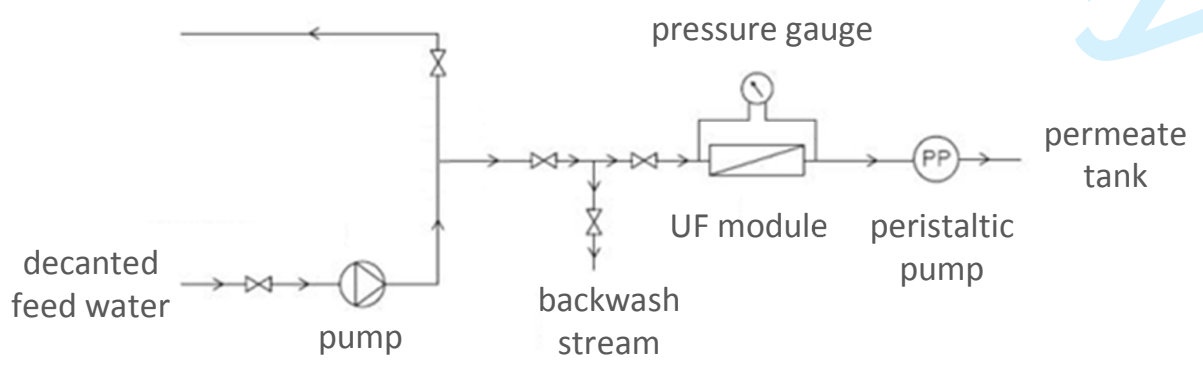

Figure 2: Schematic diagram of the experimental UF system setup. 


\subsection{Filtration procedure}

Prior to each fouling experiment, the cleaned membrane resistance $\left(R_{m}\right)$ was measured through a filtration test with deionised water. These tests were conducted in dead-end mode at a TMP of 1.2 bar without recirculation of permeate for $15 \mathrm{~min}$ and then with recirculation until constant permeate production. At this point, $\mathrm{R}_{\mathrm{m}}$ was calculated according to the well-established Darcy's equation described in Section 2.6.

Each filtration experiment was carried out at a filtration TMP of 1.2 bar and one combination of BW-related variables, i.e.: backwash TMP $\left(\mathrm{BW}_{\mathrm{TMP}}\right)$, backwash duration $\left(\mathrm{BW}_{\mathrm{d}}\right)$, backwash frequency $\left(\mathrm{BW}_{\mathrm{f}}\right)$ and chemically enhanced backwash composition $\left(\mathrm{BW}_{\mathrm{CEB}-\mathrm{c}}\right)$. For the carrying out of the experiments with CEBs the dose of $\mathrm{NaClO}$ was $7 \mathrm{mg} / \mathrm{L}$, while $\mathrm{NaOH}$ and citric acid were added to bring $\mathrm{pH}$ to $10-11$ and to $3-4$, respectively. In order to isolate the effect of these variables on fouling reversibility, each of them was varied (as shown in Table 3 ) while setting all other variables at fixed values (marked in bold in Table 3).

Table 3: Summary of the experimental conditions and variation of each set of experiments conducted during the study.

\begin{tabular}{ll} 
Variable of study & Tested values \\
\hline $\mathrm{BW}_{\mathrm{TMP}}($ bar $)$ & $0.7,1.0,1.5, \mathbf{1 . 8}$ \\
$\mathrm{BW}_{\mathrm{f}}(\mathrm{min})$ & $10, \mathbf{2 0}, 40,60$ \\
$\mathrm{BW}_{\mathrm{d}}($ min $)$ & $0.5, \mathbf{1 . 0}, 2.0$ \\
$\mathrm{BW}_{\text {CEB-c }}$ & Blank ${ }^{*}, \mathrm{NaClO}, \mathrm{NaOH}, \mathrm{NaOH}+\mathrm{NaClO}$, citric acid \\
\hline * Blank means BW with UF permeate
\end{tabular}

The pre-fixed value is marked in bold

Permeate flux and quality was monitored all over each filtration experiment, which lasted $200 \mathrm{~min}$ and was generally conducted in duplicate to ensure consistency of results. Flux was measured by the timed collection of permeate in a volumetric flask. Because feed water for all experiments was taken from the same location in the treatment train of the DWTP in Sant Joan Despí, the differences observed in fouling reversibility could be attributed to the investigated BW-related variables. 


\subsection{Removal and reversibility of organic fractions}

Further efforts were devoted to investigate which organic fractions were most removed by the UF membrane and which were most detached from it after the successive application of BW (assisted with intermittent CEB), a CIP based on alkaline and oxidant agents (CIP-B) and finally a CIP based on an acid agent (CIP-A). This allowed quantify the reversible fouling after each backwashing and cleaning step and eventually the irreversible fouling on the UF membrane.

For this purpose, a filtration experiment was conducted similarly to those described above at a constant TMP of 1.2 bar and a BW regime optimised from the previous set of experiments, i.e. BW was performed every 20 min of filtration at a TMP of 1.8 bar and with a duration of $1.0 \mathrm{~min}$. Additional CEBs based on a combination of $\mathrm{NaClO}(7 \mathrm{mg} / \mathrm{L})$ and $\mathrm{NaOH}$ (pH 10-11) were applied every $3 \mathrm{BW}$. A total volume of $3.945 \mathrm{~L}$ of feed water was filtered, of which $0.337 \mathrm{~L}$ was used for BW. On completion of the filtration experiment, the UF membrane was consecutively subjected first to the CIP-B with the addition of $\mathrm{NaOH}$ (pH between 11 and 12) in combination with $200 \mathrm{mg} / \mathrm{L} \mathrm{NaClO}$ (volume $50 \mathrm{~mL}$, contact time $90 \mathrm{~min}$ ) and, second, to the CIP-A with the addition of citric acid ( $\mathrm{pH}$ between 3 and 4, volume $50 \mathrm{~mL}$, contact time 30 $\min )$. The reagents used for CIP-B and CIP-A were selected in accordance with the ones used in the drinking water treatment plant of Sant Joan Despí.

Feed and permeate over the experiment were collected for analysis of DOC and its fractions (see below analytical techniques) by HPSEC. Organic fractionation was also performed for the successive BW streams (collected as a composite sample) and CIP-B and CIP-A solutions.

\subsection{Chemical analysis of water samples}

Feed water and UF permeate quality for the first set of experiments was analysed in terms of turbidity, TOC and $\mathrm{UV}_{254}$. The samples were collected in sterile vials and stored in cold conditions until analysis in the laboratory. Turbidity was analysed by nephelometry (Hach 2100 AN IS Turbidimeter), Absorbance was analysed by spectrophotometry (Hach DR 5000) and TOC by oxidative combustion and infrared-detection (Shimadzu V CPH).

Fractionation of dissolved organic carbon (DOC) was performed by HPSEC using a Toyopearl TSK HW-50S column (250×20 mm) coupled to on-line UV254, organic carbon (OC) and organic nitrogen $(\mathrm{ON})$ detectors by DOC-Labor (Karlsruhe). The principles of the technique are reported in depth by Huber et al. [23]. Briefly, it is based on size exclusion liquid chromatography whereby organic compounds are fractionated into five sub-fractions according to their molecular weight (MW): (1) biopolymers (BP, with $\mathrm{MW}>20000 \mathrm{~g} / \mathrm{mol}$, basically 
constituted by polysaccharides and proteins), (2) humic substances (HS, with MW of approx. $1000 \mathrm{~g} / \mathrm{mol}$, constituted by fulvic and humic acids), (3) building blocks (BB, with MW between 300 and $500 \mathrm{~g} / \mathrm{mol}$, constituted by breakdown products of humics), (4) low molecular weight acids (LMWA, with $\mathrm{MW}<350 \mathrm{~g} / \mathrm{mol}$, constituted by alcohols, aldehydes, ketones, sugars and amino acids) and (5) low molecular neutrals (LMWN, with $\mathrm{MW}<350 \mathrm{~g} / \mathrm{mol}$, constituted by alcohols, aldehydes, ketones and amino acids). The organic carbon retained in the chromatographic column (i.e. non-chromatographic DOC) is termed hydrophobic fraction. Based on the differences in UV-active components or nitrogen content, HPSEC can also determine the content of proteins within the BP fraction.

\subsection{Data treatment for the membrane hydraulic performance evaluation}

Fouling was determined by the increase of resistance posed by the fouled membrane, which was in turn calculated from the decline of permeate flux according to the well-established Darcy's equation:

$$
\mathrm{J}=\frac{\Delta \mathrm{P}}{\mu \cdot \mathrm{R}_{\text {total }}}
$$

where $\mathrm{J}$ is the permeate flux $\left(\mathrm{m}^{3} \cdot \mathrm{m}^{-2} \cdot \mathrm{s}^{-1}\right), \Delta \mathrm{P}$ is the TMP $(\mathrm{Pa}), \mu$ is the permeate viscosity $(\mathrm{Pa} \cdot \mathrm{s})$ (corrected to $20^{\circ} \mathrm{C}$ ) and $\mathrm{R}_{\text {total }}$ is the total resistance of the fouled membrane $\left(\mathrm{m}^{-1}\right)$. According to Darcy's law, a decrease in $\mathrm{J}$ under constant $\Delta \mathrm{P}$ during membrane filtration process (or equivalently an increase in $\Delta \mathrm{P}$ under constant $\mathrm{J}$ ) is indicative of membrane fouling. The total resistance can be described by the resistance-in-series model and expressed as $[4,10,13]$ :

$$
J=\frac{\Delta P}{\mu \cdot\left(R_{m}+R_{\text {rev }}+R_{\text {irrev }}\right)}
$$

where $R_{m}$ is the cleaned membrane resistance (measured before each experiment with deionised water) and $\mathrm{R}_{\text {rev }}$ and $\mathrm{R}_{\text {irrev }}$ are the hydraulically reversible and irreversible fouling resistances, respectively.

For each filtration cycle " $\mathrm{i}$ " $\mathrm{R}_{\mathrm{rev}}^{\mathrm{i}}$ was calculated as the difference of resistance measured before and after backwashing (as shown in Figure 2).

$$
\mathrm{R}_{\text {rev }}^{\mathrm{i}}=\mathrm{R}_{\text {before BW }}^{\mathrm{i}}-\mathrm{R}_{\text {after BW }}^{\mathrm{i}}
$$

The contribution of $\mathrm{R}_{\mathrm{rev}}^{\mathrm{i}}$ over the total fouling of the membrane $\left(\mathrm{R}_{\text {fouling }}\right)$ can then be calculated as follows (see Figure 1): 
Reversible fouling (\%) $=\frac{\mathrm{R}_{\text {rev }}^{\mathrm{i}}}{\mathrm{R}_{\text {fouling }}^{\mathrm{i}}}=\frac{\mathrm{R}_{\text {before } \mathrm{BW}}^{\mathrm{i}}-\mathrm{R}_{\mathrm{after} \mathrm{BW}}^{\mathrm{i}}}{\mathrm{R}_{\text {before } \mathrm{B} \mathrm{W}^{-} \mathrm{R}_{\mathrm{m}}}^{\mathrm{i}}}$

In this study, averaged reversible fouling percentages over all filtration cycles and duplicates under the same experimental conditions are reported for comparison between different BW regimes.

It must be remarked here that most published studies report experimental data on a dimensionless basis (e.g normalised flux, pressure, permeability or resistance). While this facilitates indeed comparison of experiments carried out under different experimental conditions, it also masks the possible effects of e.g. flux and pressure values on fouling. For this reason, measured fouling-related variables were not normalised and reported as measured.

\section{RESULTS}

Plotted in the next figures are a) the total resistance curves obtained for each set of BW conditions, b) the degree of membrane fouling reversibility calculated from the resistance profile and according to eq. 2 , and c) the quality of permeate in terms of turbidity, $\mathrm{UV}_{254}$ and TOC. In all cases, resistance profile showed a pattern as described in Figure 1, i.e. an increase in resistance during the filtration step and a decrease during BW. The resistance was however not completely restored to the initial value, indicating that, regardless the BW regime, irreversible foulants slowly accumulated onto and into the membrane.

\subsection{Effect of backwashing transmembrane pressure $\left(\mathrm{BW}_{\text {TMP }}\right)$}

As shown in Figure 3, higher $\mathrm{BW}_{\mathrm{TMP}}$ provided a lower resistance increase (i.e. a better permeability restoration) over the experiment (Figure 3a) and a higher degree of fouling reversibility (Figure $3 \mathrm{~b}$ ). $\mathrm{R}_{\text {rev }}$ percentage was below $30 \%$ at $\mathrm{BW}_{\text {TMP }}$ of 0.7 and 1.0 bar, but it increased to $31 \%$ at $\mathrm{BW}_{\mathrm{TMP}}$ of 1.5 bar and up to $41 \%$ at $\mathrm{BW}_{\mathrm{TMP}}$ of 1.8 bar. This trend is likely due to the fact that shearing stress can more efficiently wash out tightly bound foulants from the membrane that would not be removed by lower $\mathrm{BW}_{\mathrm{TMP}}$.

This finding is partially in accordance with that reported by Remize et al. [10], who observed that increasing $\mathrm{BW}_{\mathrm{TMP}}$ from 1.2-2.0 bar in the filtration of surface water with UF membranes resulted in an increase of the foulants removed from the membrane (from $25 \%$ to $44 \%$ ). Interestingly, and in opposition to our study, this trend did not translate into an increase of permeability recovery with $\mathrm{BW}_{\mathrm{TMP}}$, highlighting that measurement of permeability (or 
a)

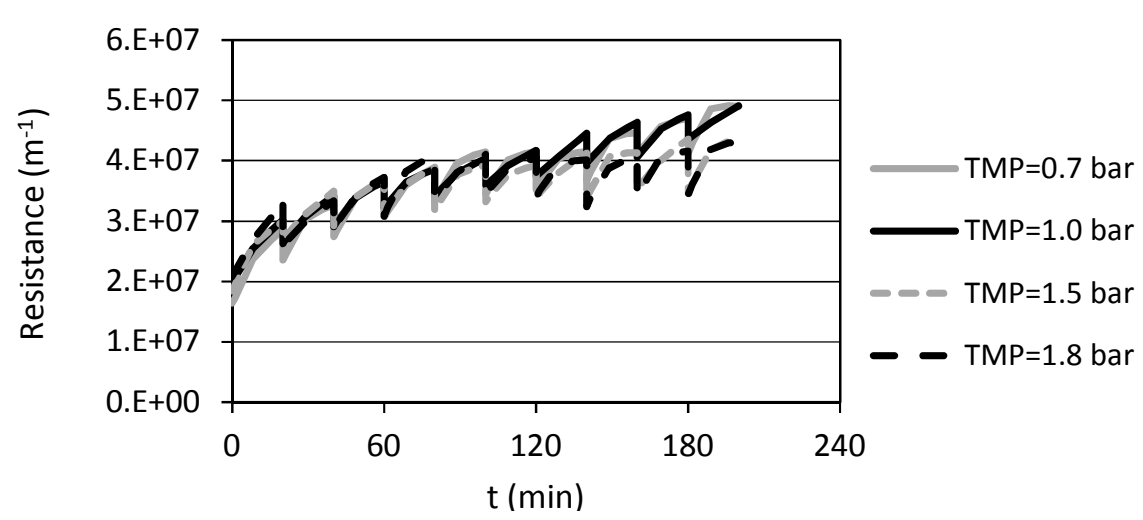

b)

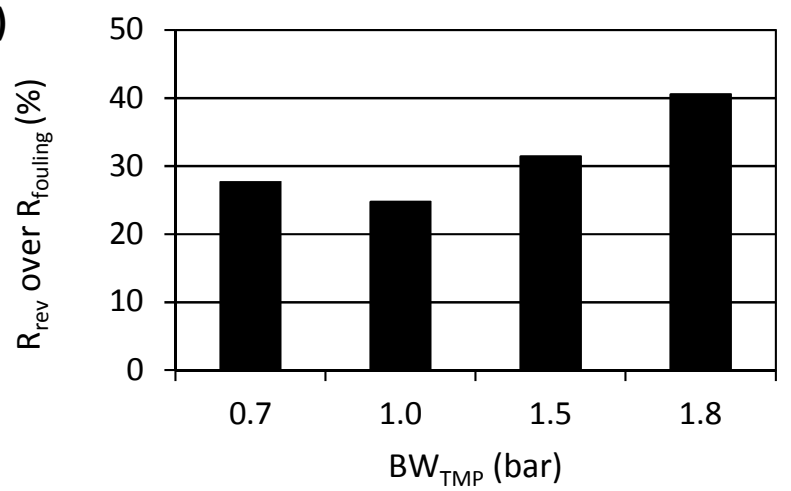

c)

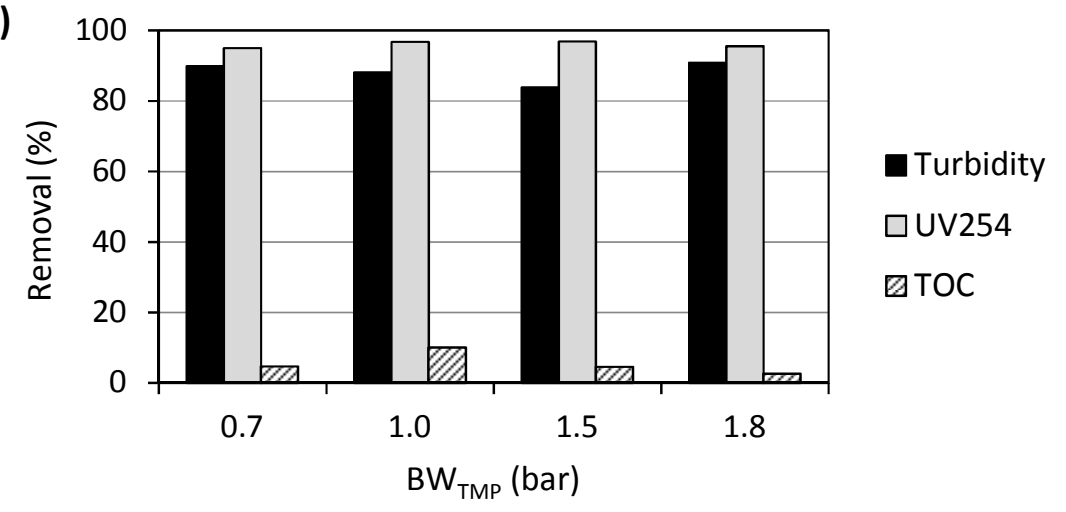


Figure 3: Effect of backwash transmembrane pressure $\left(\mathrm{BW}_{\mathrm{TMP}}\right)$ on the a) total resistance of the fouled membrane, $b$ ) percentage of reversible fouling over the total membrane fouling and c) removal of turbidity, $\mathrm{UV}_{254}$ and TOC by the UF membrane (confidence intervals $\leq 4.5 \%$ at a confidence level of $95 \%$ for all cases).

\subsection{Effect of $B W$ frequency $\left(B W_{f}\right)$}

The effect of $\mathrm{BW}_{\mathrm{f}}$ on the total resistance, fouling reversibility and permeate quality during the process of membrane filtration is shown in Figure 4. It is noticeable in Figure 4a that the initial resistance for $\mathrm{BW}_{\mathrm{f}}=10$ min was slightly higher than that corresponding for all other $\mathrm{BW}_{\mathrm{f}}$, suggesting that permeability membrane before that experiment had not been completely restored. Even so, backwashing every $10 \mathrm{~min}$ resulted in a lower fouling rate, in contrast to backwashing at stretched frequencies (20,40 and $60 \mathrm{~min})$, which led to a more severe increase in fouling resistance (i.e. accumulation of irreversible fouling) during membrane operation. As shown in Figure $4 \mathrm{~b}$, the more frequent the BW the higher the reversibility of fouling: fouling reversibility decreased from $50 \%$ for $\mathrm{BW}_{\mathrm{f}}$ of 10 min to $41 \%$ for $\mathrm{BW}_{\mathrm{f}}$ of 20 min and below $37 \%$ for both $\mathrm{BW}_{\mathrm{f}}$ of 40 and $60 \mathrm{~min}$.

Similar trends on lowered fouling accumulation with more frequent BW have been reported by other researchers, although the degree of dependence differ considerably if other types of feed water or UF configurations are used as it is commonly the case [2,5,12]. There is, however, consensus that stretched BW frequencies allow more material to be accumulated on the membrane surface during a filtration cycle, forming a fouling layer more tightly attached and compacted and exhibiting thus a lower degree of reversibility under a given BW $[1,6,16]$.

Concerning the permeate quality, no significant differences were observed neither under the different $\mathrm{BW}_{\mathrm{f}}$ tested nor compared with the previous set of experiments under different $\mathrm{BW}_{\mathrm{TMP}}$. Turbidity and $\mathrm{UV}_{254}$ removals were $88 \%$ and $95 \%$, respectively, whereas TOC removal was only $5 \%$. 


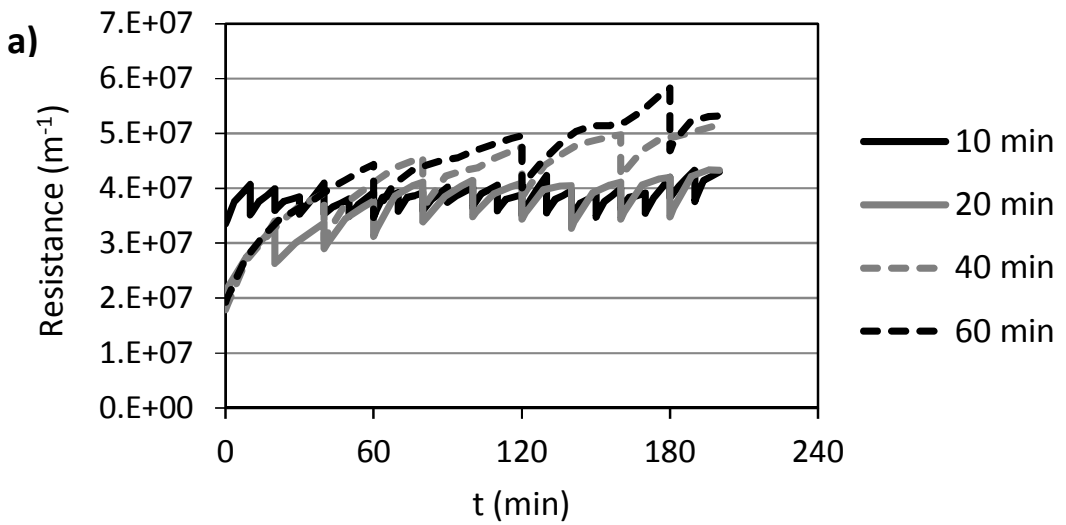

b)

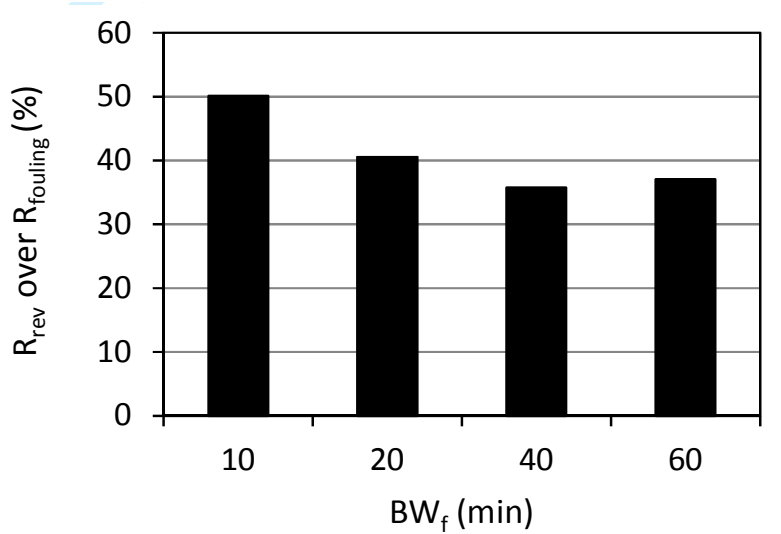

c)

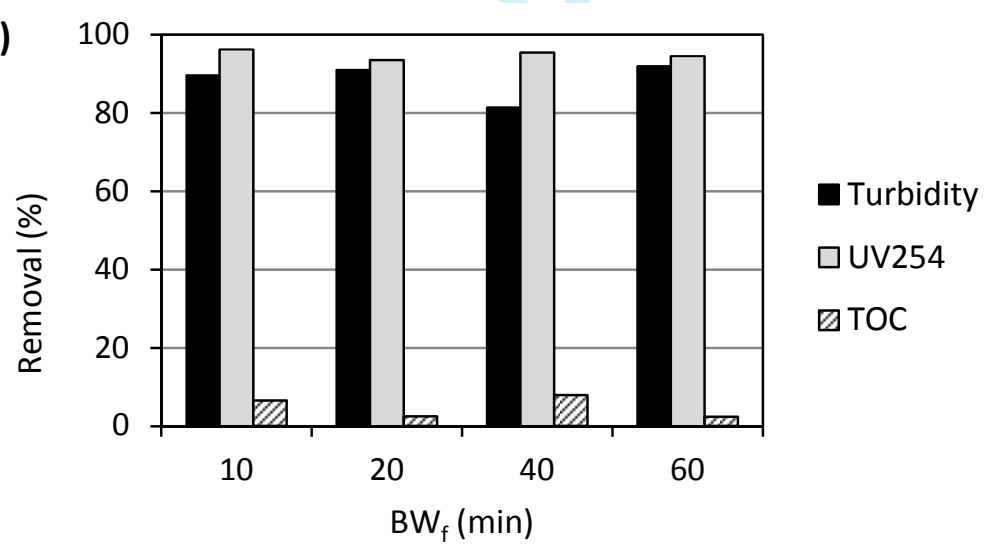

Figure 4: Effect of backwash frequency $\left(\mathrm{BW}_{\mathrm{f}}\right)$ on the a) total resistance of the fouled membrane, b) percentage of reversible fouling over the total membrane fouling and c) removal of turbidity, absorbance and TOC by the UF membrane (confidence intervals $\leq 7.6 \%$ at a confidence level of $95 \%$ for all cases). 


\subsection{Effect of $B W$ duration $\left(B W_{d}\right)$}

The effect of $\mathrm{BW}_{\mathrm{d}}$ on the total resistance, fouling reversibility and permeate quality during the process of membrane filtration is shown in Figure 5. As in the previous set of experiments, an experiment showed an initial membrane resistance slightly higher than the corresponding to the other experiments, suggesting again that the membrane was not completely cleaned prior to the filtration experiment. Despite the different starting point, the evolution of resistance over all experiments is comparable.

Increasing $\mathrm{BW}_{\mathrm{d}}$ from $0.5 \mathrm{~min}$ to $1 \mathrm{~min}$ increased the fouling reversibility from $32 \%$ to $41 \%$, indicating that foulants are more easily washed out away from the membrane pores during a longer backwash (Figure 5b). In fact, better fouling removal from UF membrane at increased $\mathrm{BW}_{\mathrm{d}}$ has been reported in the scientific literature for very variable filtration scenarios in terms of feed water characteristics and UF configurations [1,2,5,6,16-18], including other types of membrane systems such as microfiltration [9], ceramic membranes [25] and membrane bioreactors [26].

In our study, lengthening the $\mathrm{BW}_{\mathrm{d}}$ to 2 min was not accompanied by any increase of fouling reversibility. The existence of a threshold in $\mathrm{BW}_{\mathrm{d}}$ beyond which no further improvement is observed has also been observed by other researchers [1,23]. Ye et al. [1] attributed this trend to the fact that "excess backwash volume might also foul the membrane or the remaining fouling cake due to the impurities in the backwash flux".

Similarly to the previous set of experiments, turbidity and $\mathrm{UV}_{254}$ removals were removed at high extents ( $83 \%$ and $94 \%$, respectively), whereas TOC removal was only $2 \%$ (with the exception at $\mathrm{BW}_{\mathrm{d}}$ of 0.5 when a TOC removal of $22 \%$ was attained). 
a)

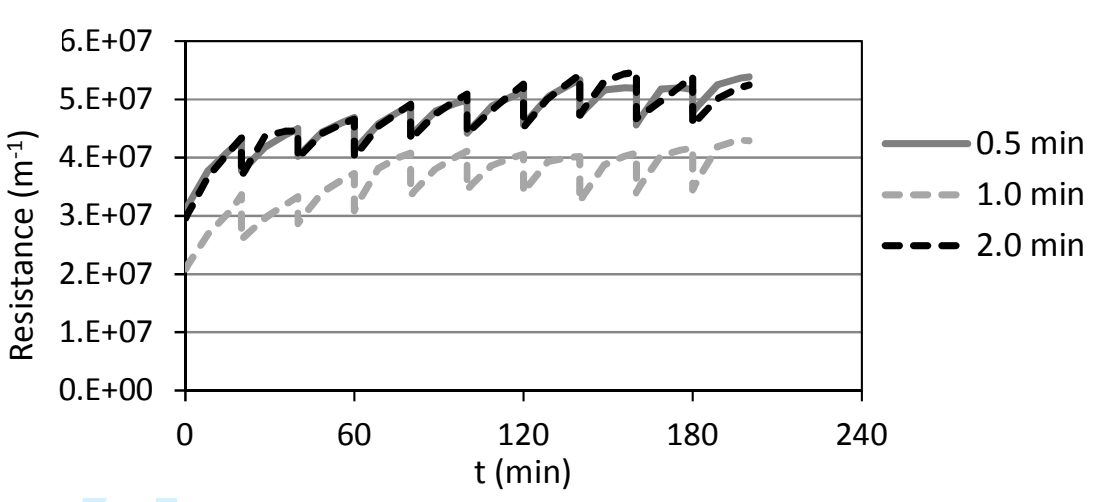

b)

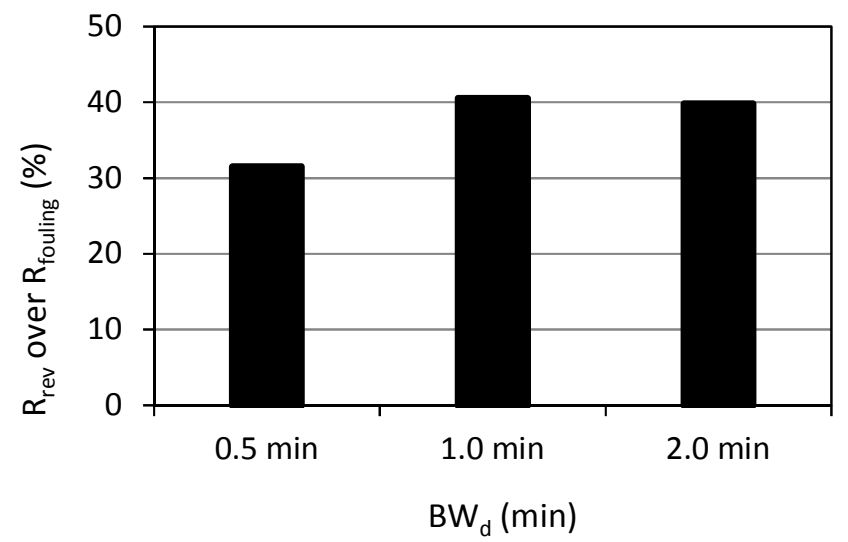

c)

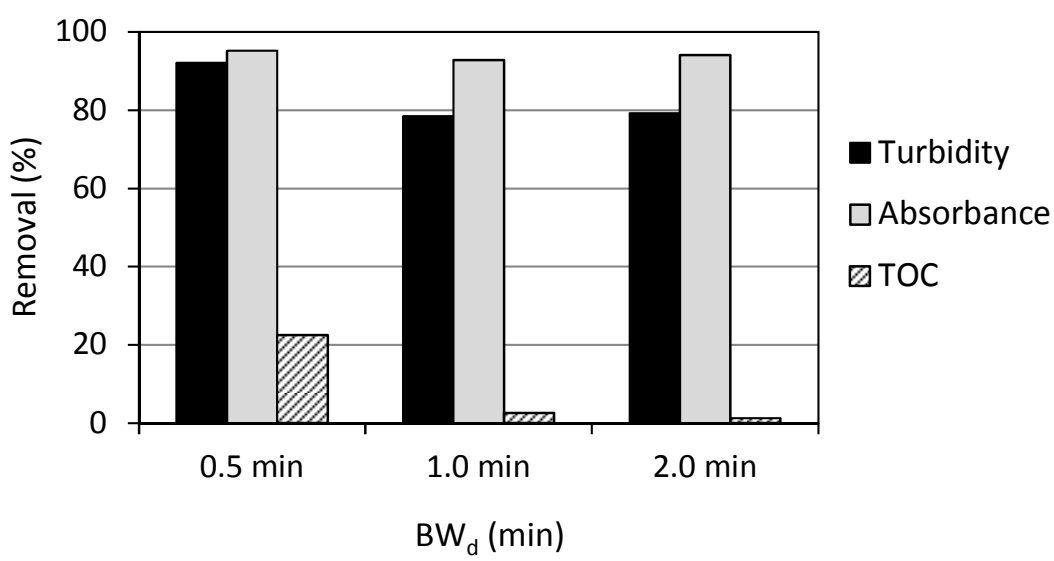

Figure 5: Effect of backwash duration $\left(\mathrm{BW}_{\mathrm{d}}\right)$ on the a) total resistance of the fouled membrane, b) percentage of reversible fouling over the total membrane fouling and c) removal of turbidity, $\mathrm{UV}_{254}$ and TOC by the UF membrane (confidence intervals $\leq 4.5 \%$ at a confidence level of $95 \%$ for all cases). 


\subsection{Effect of the chemically enhanced BW composition (BW $\left.\mathrm{BEB-c}_{\mathrm{C}}\right)$}

The fouling rate and reversibility degree differed depending on the chemical cleaners used for the $\mathrm{CEB}$ (Figure 6). NaClO performed the best, exhibiting the lowest fouling rate and the maximum fouling reversibility degree (approx. 38\%), closely followed by the combination of $\mathrm{NaOH}+\mathrm{NaClO}$ (approx. 34\%). Acidic and alkaline cleaning solutions are commonly employed to remove inorganic and organic foulants, respectively, but the use of citric acid and $\mathrm{NaOH}$ in this study contributed little to the reversibility of fouling (approx. 28-27\%) compared to the blank (26\%) (Figure 6b).

These results compare well with those reported by Arnal et al. [7] and Zheng et al. [12], who found that $\mathrm{NaClO}$ as a cleaner added to the $\mathrm{BW}$ water performed the best at restoring the permeability of a UF membrane fouled after treatment of surface water [7] and wastewater [12], while $\mathrm{NaOH}$ had less influence compared to water. Similar results were observed by Espinasse et al. [29] after treating coupons of nanofiltration membrane with various cleaning agents. The benefits of using $\mathrm{NaClO}$ are explained by the fact that $\mathrm{NaClO}$ can oxidise the organic foulants accumulated on the membrane, generating more oxygen-containing functional groups (such as ketone, aldehyde and carboxylic acids), which due to their increased hydrophilicity are less attached to the membrane $[12,29,30]$. To exemplify the disinfection power of some chlorinebased compounds, Laine et al. [31] reported that ceasing the dosage of chlorine in backwash water after 20 days of operation resulted in severe fouling of the membranes within 5 days. Alkaline agents have also been reported to be effective at detaching foulants (particularly organic ones) since at high $\mathrm{pH}$ many organic compounds are hydrolysed presenting, under their dissociated form, increased solubility and propensity to be detached from the membrane [29].

Beyond the use of oxidant and alkaline agents separately, their combination has also been reported to be more effective at removing foulants from the membrane $[29,30,32]$. However, the combination of $\mathrm{NaClO}$ and $\mathrm{NaOH}$ in this study did not perform better than $\mathrm{NaClO}$ alone (Figure 6). The low performance of citric acid, which is effective for the removal of inorganic foulants via dissolution of salts and complexation of certain metals, is indicative that the fouling layer formed on the membrane was made up of organic materials rather than inorganic salts. 
a)

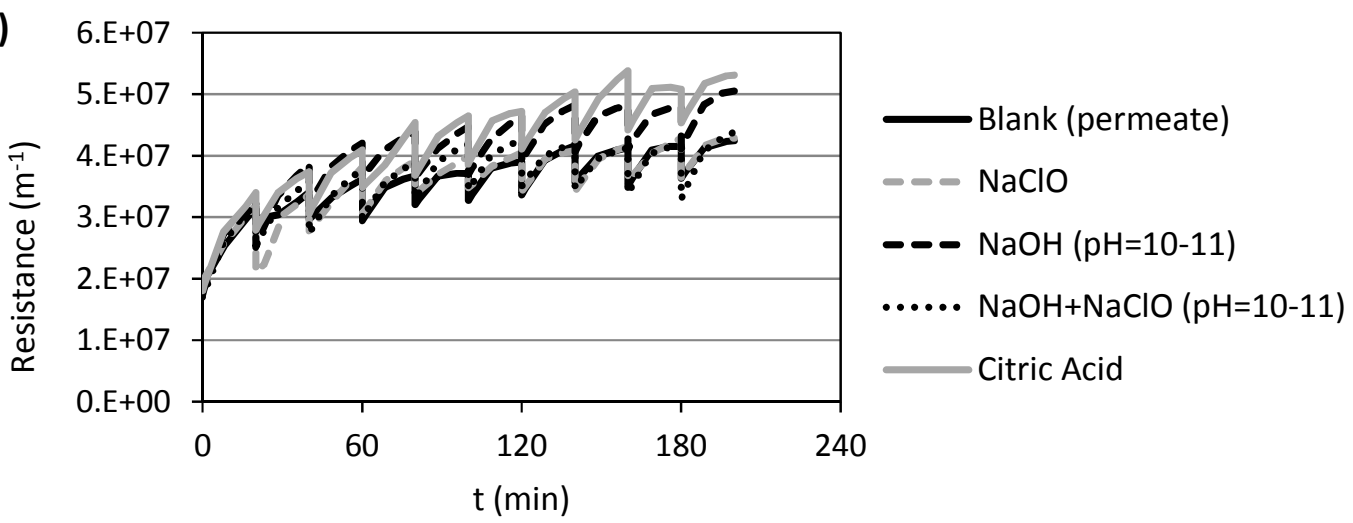

b)

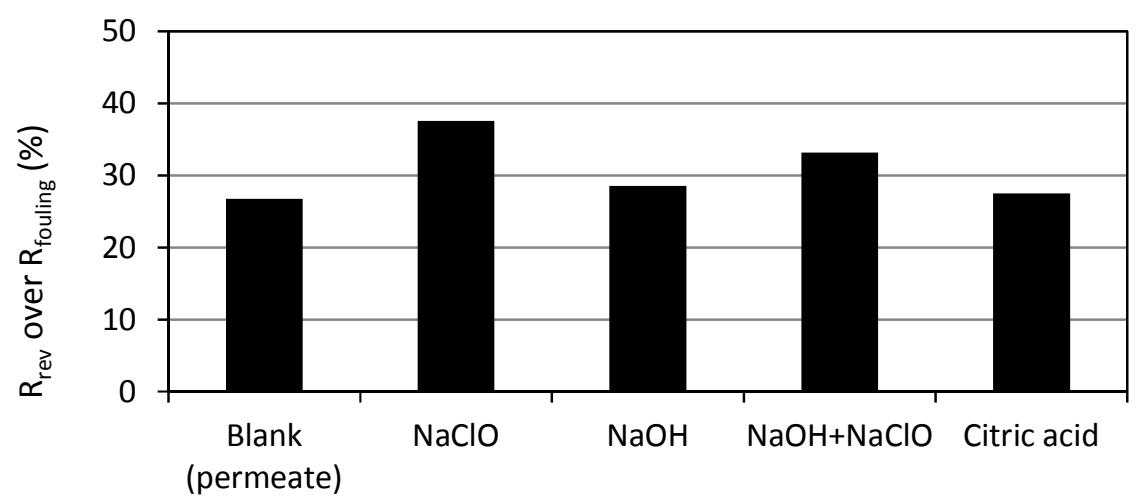

Chemical agent

Figure 6: Effect of the $\mathrm{CEB}$ composition $\left(\mathrm{BW}_{\mathrm{CEB}-\mathrm{c}}\right)$ on the a) total resistance of the fouled membrane, b) percentage of reversible fouling over the total membrane fouling by the UF membrane (confidence intervals $\leq 4.0 \%$ at a confidence level of $95 \%$ for all cases).

\subsection{Organic fouling composition on the UF membrane}

Figure 7 compares the concentration of TOC, DOC and each of the organic fraction in feed and permeate (with removal percentages in brackets) as analysed by HPSEC.

Feed water showed TOC and DOC values of 4.0 and $3.3 \mathrm{mg} / \mathrm{L}$, respectively. This difference (of 15\%) indicated that even this water had passed through a sand filtration stage a fraction of the organic load was still in the form of particular or colloidal organic carbon. With regards to the organic fractions, HS was always the most predominant one, accounting for $56 \%$ of the total DOC, followed by the lighter BB and LMWN (20\%) fractions, while the heavier BP fraction averaged only 4\%. The LMWA fraction was always found below limit detection. This composition is in accordance with previous studies that also applied HPSEC for the fractionation of NOM after sand filtration of river water [33,34]. 


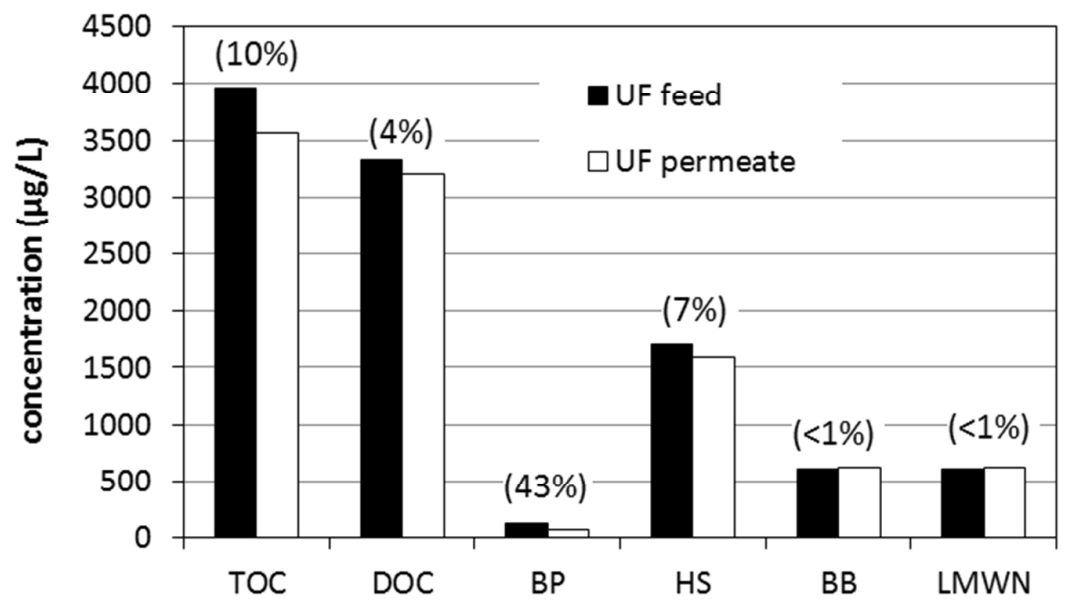

Figure 7: Concentration of TOC, DOC and its fractions BP, HS, BB and LMWN in both feed and permeate streams (in brackets removal percentages by UF the membrane)

The removal of TOC by the UF membrane was $10 \%$, while the corresponding one for DOC was fairly low (4\%). Larger differences in the removals were observed for the different organic fractions. UF membrane preferentially removed the heaviest (and biggest) fraction BP (removal percentage of $43 \%$ ), while intermediate HS was removed at a percentage of $7 \%$ and lighter (and smaller) BB and LMWN seemed to entirely pass through the UF membrane. This finding is in agreement with Peter-Varbanets et al. [35], who also observed that "only biopolymers and the humic acid fraction of NOM were retained to some extent during filtration" of different types of water. The fact that BP was in percentage the most retained material was expected based on size exclusion effects [22,36,37] and was in accordance with other studies that have observed a flux decline through UF membrane when the concentration of BP was increased within a range of concentrations similar to that in the present study $[35,38,39]$.

Based on a comparison between the composition of feed and permeate streams, fouling on UF membranes was anticipated to be made up of $67 \%$ HS (amounting $469 \mu \mathrm{g}$ ) and 33\% BP (amounting $229 \mu \mathrm{g}$ ) (percentages referred to the total DOC removed by UF). It is of note that $20 \%$ of the $229 \mu \mathrm{g}$ of BP retained on the UF membrane consisted of protein-like compounds, indicating preferential removal of polysaccharides over proteinaceous substances. This is in agreement with other researchers that have applied HPSEC in the ultrafiltration of water [22].

\subsection{Fouling detachment after each backwashing and cleaning}

UF membranes are periodically backwashed with ultrafiltered water to remove deposited matter from the membrane and restore its original permeability as much as possible. 
Detachment of organic matter from the UF membrane was evident as the backwash stream was richer in absolute TOC concentration $(4.7 \mathrm{mg} / \mathrm{L})$ than ultrafiltered water used for the backwash (3.6 mg/L). The composition of such backwash stream was 9\% BP, 51\% HS, 20\% BB and 20\% LMWN. In comparison with the ultrafiltered permeate, it was found to be enriched in BP (by $5 \%$ ) and impoverished in HS (by 5\%), while the concentrations of BB and LMWN were essentially the same.

Figure 9 compares the initial organic mass (in $\mu \mathrm{g}$ ) fouling the UF membrane with the mass remaining after applying BW (+CEBs), CIP-B and CIP-A calculated through a massbalance from the concentration of each organic fraction within each volume stream.

It can be seen that BW(+CEBs) was able to detach $33 \%$ of the initial BP but only $9 \%$ of the initial HS. The enrichment in BP suggested that components within this fraction, in particular polysaccharides rather than proteins, were not rigidly attached to the membrane but amenable to be washed out. This behaviour is likely due essentially to their size relative to that of the membrane pores: organic substances within the BP fraction much larger than the membrane pores lead to cake formation, which is more readily detached, while lighter fractions such as HS can cause pore blocking, build-up a denser cake layer less readily washed out or be adsorbed onto the membrane material [8,32]. The remaining BP and HS on the membrane would explain the irreversible fouling (never completely avoided whatever the BW regime applied) that resulted in the gradual increase of total resistance over time (Figures 3-6). Which is of these fractions has a larger impact on the membrane resistance is not clear.

HS was found in this study to be the most retained fraction in terms of amount (but not of percentage) (Figure 8). HS is considered by some studies of minor relevance in terms of fouling due to their high transmission through the mesoporous UF membrane $[22,38,39]$, whereas it is considered a detrimental foulant causing severe hydraulically irreversible fouling by some others [40].

Opposite to HS, BP was found to be the most retained fraction in terms of percentage (but not of amount) (Figure 8), in agreement with other previous studies [20,22]. Its impact on fouling depends however upon its components: polysaccharides are believed to cause only hydraulically reversible fouling, while protein-like substances are thought to induce hydraulically irreversible fouling [22,39]. The major impact of proteins on fouling may be caused to the fact that they are more compact and can be retained at or inside the pores, thus resulting in the constriction and/or blockage of the membrane pores [39]. The finding in this study that $20 \%$ of the BP retained by the UF membrane was made of protein-like substances may explain why BP was not completely detached after the application of BW $(+\mathrm{CEB})$ (Figure 9).

In this study, because a portion of both BP and HS fractions were attached on the UF membrane, it could not be elucidated whether fouling was mainly caused by one or another (or 
both) fraction. Clearly, more investigations are required to identify if HS or BP contributes most to hydraulically (ir)reversible membrane fouling during UF of different waters.

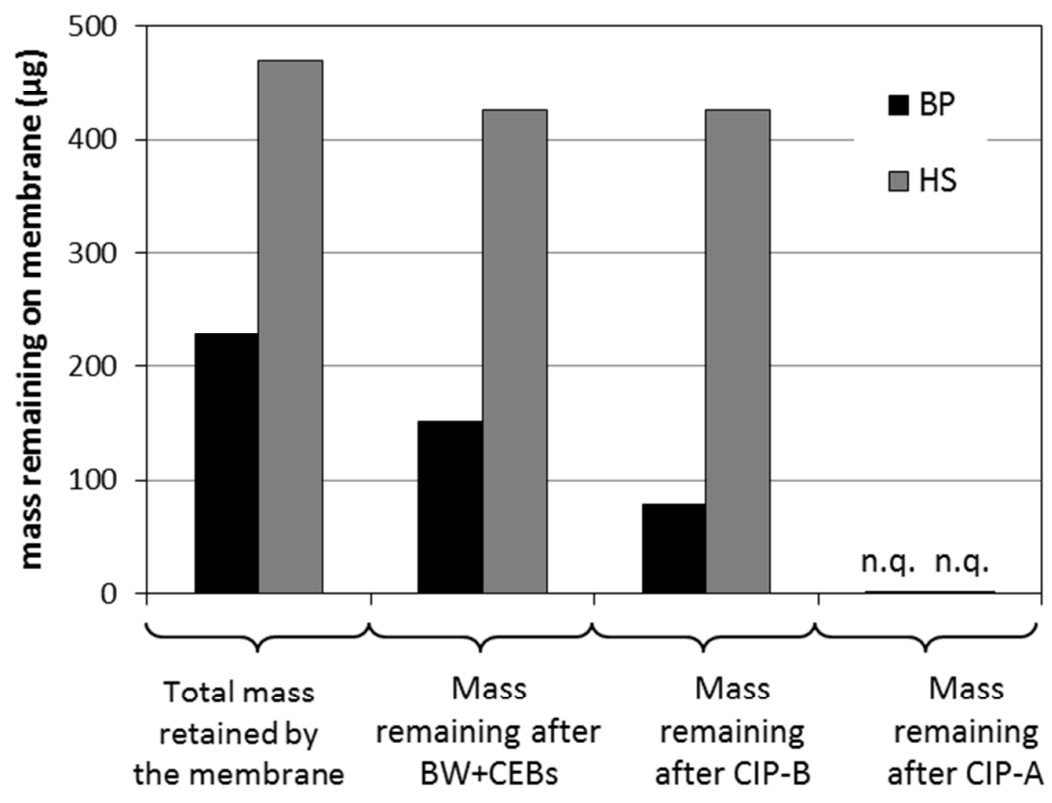

Figure 9: Evolution of mass of BP and HS remaining on the UF membrane ( $\mu \mathrm{g})$ after the successive application of BW (+CEBs), CIP-B and CIP-A.

Soaking the membrane with the CIP-B solution resulted in a detachment of a further $32 \%$ of the initial BP retained by the membrane, but on contrary no HS was detached at all, corroborating that this fraction was rigidly tight to the membrane and not easily detached by $\mathrm{NaOH}$ either $\mathrm{NaClO}$ under the experimental conditions of this study. As mentioned above in this study, the detachment of BP may be explained by the fact that the constituents of the BP fraction (polysaccharides, proteins) are hydrolised at high $\mathrm{pH}$ (even the weakest phenolic groups dissociate at such a high $\mathrm{pH}$ ) and oxidised, increasing their solubility and therefore being more prone to be detached from the membrane [29]. Finally, the performance of an acid solution (CIP-A) could not be quantified because the organic fractions detached, if any, might be in the HPSEC chromatograms overwhelmed by the very high concentration of citric acid employed as cleaning agent. However, and also according with what was discussed in previous sections, organic fouling detachment is expected to be of minor importance since acid cleanings are applied commonly to eliminate inorganic foulants from the membrane (e.g. Fe and Mn) [32]. This is in qualitative agreement with Strugholtz et al., who found that $\mathrm{NaOH}$ and in particular $\mathrm{NaClO}$ were effective at removing both $\mathrm{BP}$ and $\mathrm{HS}$ while $\mathrm{HCl}$ was not [32]. The fact that organic fractions were analysed in their study only in the cleaning solution did not allow 
determine how much BP and HS were remaining on the membrane and, hence, compare results with the ones obtained in this study.

\section{CONCLUSIONS}

Reversibility of fouling on a bench-scale UF membrane treating decanted water under different BW regimes was assessed in this study. The BW regimes were varied in terms of backwash TMP $\left(\mathrm{BW}_{\mathrm{TMP}}\right)$, backwash duration $\left(\mathrm{BW}_{\mathrm{d}}\right)$, backwash frequency $\left(\mathrm{BW}_{\mathrm{f}}\right)$ and chemically enhanced backwash composition $\left(\mathrm{BW}_{\mathrm{CEB}-\mathrm{c}}\right)$. Permeate quality was monitored in terms of turbidity, $\mathrm{UV}_{254}$ and TOC.

Although differing in their efficiency, all BW regimes proved to contribute to control fouling on UF membranes. Nevertheless, results also showed that irreversible fouling was never completely avoided whatever the BW regime applied, resulting in a gradual increase of total resistance over time. Splitting the $\mathrm{R}_{\text {fouling }}$ into its components, it was found that $\mathrm{R}_{\text {irrev }}$ was always higher than $\mathrm{R}_{\mathrm{rev}}$.

As expected, the degree of reversibility depended on the BW-related variables. Higher $\mathrm{BW}_{\text {TMP }}$ provided higher degrees of fouling reversibility, with $\mathrm{R}_{\text {rev }}$ percentage below $30 \%$ at $\mathrm{BW}_{\mathrm{TMP}}$ of 0.7 and 1.0 bar, but of $31 \%$ at $\mathrm{BW}_{\mathrm{TMP}}$ of 1.5 bar and up to $41 \%$ at $\mathrm{BW}_{\mathrm{TMP}}$ of 1.8 bar. Concerning the $\mathrm{BW}_{\mathrm{f}}$, the more frequent the $\mathrm{BW}$ the higher the reversibility of fouling: fouling reversibility decreased from $50 \%$ at $\mathrm{BW}_{\mathrm{f}}$ of $10 \mathrm{~min}$ to $41 \%$ at $\mathrm{BW}_{\mathrm{f}}$ of $20 \mathrm{~min}$ and below $37 \%$ at both $\mathrm{BW}_{\mathrm{f}}$ of 40 and $60 \mathrm{~min}$. Similarly, increasing $\mathrm{BW}_{\mathrm{d}}$ from $0.5 \mathrm{~min}$ to $1 \mathrm{~min}$ increased the fouling reversibility from $32 \%$ to $41 \%$, but lengthening the $\mathrm{BW}_{\mathrm{d}}$ to 2 min was not accompanied by any further increase of fouling reversibility. To sum up, the more intensive a BW was (in terms of higher $\mathrm{BW}_{\mathrm{TMP}}$, shortened $\mathrm{BW}_{\mathrm{f}}$ and prolonged $\mathrm{BW}_{\mathrm{d}}$ ) the more effective it was in removing foulants from the membrane. This was so because less intensive $\mathrm{BW}$ allowed more material to be accumulated on the membrane surface during a filtration cycle, forming a fouling layer more tightly attached and compacted and exhibiting thus a lower degree of reversibility under a given BW.

Concerning the composition of $\mathrm{CEB}, \mathrm{NaClO}$ performed the best, exhibiting the maximum fouling reversibility percentage (approx. 38\%), closely followed by the combination of $\mathrm{NaOH}+\mathrm{NaClO}$ (approx. 34\%), while citric acid and $\mathrm{NaOH}$ contributed little (approx. 28$27 \%)$ compared to the blank (26\%).

With regards to the permeate quality, no significant differences were observed whatever the BW regime applied. Turbidity and $\mathrm{UV}_{254}$ removals were always above $80 \%$ and $90 \%$, respectively, whereas TOC removal was generally below $10 \%$. The low retention of TOC may 
be explained by the predominance of small molecular weight (MW) organic fractions with $\mathrm{MW} \leq 1000 \mathrm{Da}$ (much smaller than the nominal MWCO of the UF membrane of $300000 \mathrm{Da}$ ) present in the decanted water as determined in the subsequent experiments.

While applying more intensive $\mathrm{BW}$ (in terms of higher $\mathrm{BW}_{\mathrm{TMP}}$, shortened $\mathrm{BW}_{\mathrm{f}}$ and prolonged $\mathrm{BW}_{\mathrm{d}}$ ) results in reduced membrane fouling, it also leads to higher water losses, energy consumption and chemicals requirements if CEB is applied, bringing down the operational efficiency of the UF treatment. A compromise solution must be taken to establish the optimal BW conditions that minimise both membrane fouling and total costs.

Besides optimising the BW efficiency, new approaches to minimise membrane fouling have been researched. These include other physical methods to remove foulants from a membrane surface such as flushing, vibrations, air assisted $\mathrm{BW}, \mathrm{CO}_{2}$ back permeation or combination of them [41]. Examples of such approaches are the works carried out by Bessiere et al. [42], who reported that coupling flushing with air assisted BW significantly reduced membrane fouling leading to energy savings of $65 \%$ compared to conventional $\mathrm{BW}$ when treating surface water with hollow-fibre UF modules; and Chen et al. [11], who found by employing a statistical factorial design that the optimal UF physical cleaning protocol consisted of a combination of BW followed by forward flushing when treating wastewater with a spiral wound UF system. All these studies conclude that minimising membrane fouling is still an open research field and that further efforts are required to develop optimised cleaning procedures.

With regards to the fouling potential and reversibility of the organic fractions as analysed by HPSEC, UF membrane preferentially retained the heaviest (and biggest) fraction BP (removal percentage of $43 \%$ ), while intermediate HS was retained at a percentage of $7 \%$ and lighter (and smaller) BB and LMWN seemed to entirely pass through the UF membrane. The pattern was expected from size exclusion effects [22,36,37]. Based on a mass-balance over the UF membrane, fouling was anticipated to be made up of $67 \% \mathrm{HS}$ and $33 \% \mathrm{BP}$.

The application of BW(+CEBs) resulted in the detachment of $33 \%$ of the initial BP but only $9 \%$ of the initial HS. This revealed that HS was more rigidly attached to the membrane whereas BP (in particular polysaccharides rather than protein-like substances) was more amenable to be washed out. Which of the fractions (BP or HS) remaining on the membrane contributed most on the irreversible fouling could not be elucidated in this study, but recent studies have concluded that protein-like substances represent a detrimental foulant that induce severe hydraulically irreversible fouling. This agrees with the finding that $20 \%$ of the BP fouling the UF membrane in this study consisted of proteinaceous materials.

Soaking the membrane with an alkaline and oxidant solution (CIP-B) resulted in the detachment of a further $32 \%$ of the initial BP retained by the membrane, but on contrary no HS was detached at all. Finally, the performance of an acid solution (CIP-A) could not be quantified in this study because the organic fractions detached, if any, might be in the HPSEC 
chromatograms overwhelmed by the very high concentration of citric acid employed as cleaning agent. However, organic fouling detachment is expected to be of minor importance since acid cleanings are applied commonly to eliminate inorganic foulants from the membrane (e.g. Fe and $\mathrm{Mn})$.

\section{ACKNOWLEDGEMENTS}

The authors gratefully acknowledge the personnel at Sant Joan Despí plant for their support and assistance throughout the study. This research was financially supported by ACC1O through the OPTIMECA project (RD08-2-0023).

\section{REFERENCES}

[1] Y. Ye, L.N. Sim, B. Herulah, V. Chen and A.G. Fane, Effects of operating conditions on submerged hollow fibre membrane systems used as pre-treatment for seawater reverse osmosis, J. Membr. Sci., 365 (2010) 78-88.

[2] L. Wang, X. Wang and L. Fukushi, Effects of operational conditions on ultrafiltration membrane fouling, Desalination, 229 (2008) 181-191.

[3] G.F. Crozes, J.G. Jacangelo, C. Anselme and J.M. Laîné, Impact of ultrafiltration operating conditions on membrane irreversible fouling, J. Membr. Sci., 124 (1997) 63-76.

[4] E.K. Lee, V. Chen and A.G. Fane, Natural organic matter (NOM) fouling in low pressure membrane filtration - effect of membranes and operation modes, Desalination, 218 (2008) 257-270.

[5] J. Decarolis, S. Hong and J. Taylor, Fouling behavior of a pilot scale inside-out hollow fiber UF membrane during dead-end filtration of tertiary wastewater, J. Membr. Sci., 191 (2001) 165-178.

[6] J. Kim and F.A. DiGiano, A two-fiber, bench-scale test of ultrafiltration (UF) for investigation of fouling rate and characteristics, J. Membr. Sci., 271 (2006) 196-204.

[7] J.M. Arnal, B. Garcia-Fayos, M. Sancho and G. Verdu, Ultrafiltration membrane cleaning with different chemical solutions after treating surface water, Desalin. Water Treat., 7 (2009) 198-205.

[8] K. Katsoufidou, S.G. Yiantsios and A.J. Karabelas, A study of ultrafiltration membrane fouling by humic acids and flux recovery by backwashing: Experiments and modelling, J. Membr. Sci., 266 (2005) 40-50. 
[9] L. Yang, Z. Wang, Y. Sun, Z. Hu, S. Zhao, X. Wang, W. Li, X. Xi, J. Zhang and Z. Pei, Influence of various operating conditions on cleaning efficiency in sequencing batch reactor (SBR) activated sludge process. Part II: Backwash and water rinsing introduced membrane filtration process, Desalination, 272 (2011) 76-84.

[10] P.J. Remize, C. Guigui and C. Cabassud, Evaluation of backwash efficiency, definition of remaining fouling and characterisation of its contribution in irreversible fouling: Case of drinking water production by air-assisted ultra-filtration, J. Membr. Sci., 355 (2010) 104111.

[11] J.P. Chen, S.L. Kim and Y.P. Ting, Optimization of membrane physical and chemical cleaning by a statistically designed approach, J. Membr. Sci., 219 (2003) 27-45.

[12] X. Zheng, M. Ernst and M. Jekel, Stabilizing the performance of ultrafiltration in filtering tertiary effluent - Technical choices and economic comparisons, J. Membr. Sci., 366 (2011) 82-91.

[13] S. Peldszus, C. Hallé, R.H. Peiris, M. Hamouda, X. Jin, R.L. Legge, H. Budman, C. Moresoli and P.M. Huck, Reversible and irreversible low-pressure membrane foulants in drinking water treatment: Identification by principal component analysis of fluorescence EEM and mitigation by biofiltration pretreatment, Water Res., 45 (2011) 5161-5170.

[14] S. Li, S.G.J. Heijman, J.Q.J.C. Verberk, A.R.D. Verliefde, A.J.B. Kempermand, J.C. van Dijka and G. Amy, Impact of backwash water composition on ultrafiltration fouling control, J. Membr. Sci., 344 (2009) 17-25.

[15] C. Lin, A.Y. Lin, P.S. Chandana and C. Tsai, Effects of mass retention of dissolved organic matter and membrane pore size on membrane fouling and flux decline, Water Res., 43 (2009) 389-394.

[16] Y. Yun, P. Le-Clech, C. Tang and J. Mao, Effects of operating conditions on hollow fiber membrane systems used as pretreatment for spandex wastewater reverse osmosis, Desalin. Water Treat., 34 (1-3) 423-428.

[17] A.G. Pervov, A.P. Andrianov, R.V. Efremov, A.V. Desyatov and A.E. Baranov, A new solution for the Caspian Sea desalination: low-pressure membranes, Desalination, 157 (2003) 377-384.

[18] S. Li, S.G.J. Heijman, J.Q.J.C. Verberk, G.L. Amy and J.C. van Dijk, Seawater ultrafiltration fouling control: Backwashing with demineralised water/SWRO permeate, Sep. Purif. Technol., 98 (2012) 327-336.

[19] A.L.E. Fratila, M.D. Kennedy, J.D. Linton, I. Blumed and J. Schippers, Influence of membrane morphology on the flux decline during dead-end ultrafiltration of refinery and petrochemical waste water, J. Membr. Sci., 182 (2001) 151-159. 
[20] J. Haberkamp, M. Ernst, U. Böckelmann, U. Szewzyk and M. Jekel, Complexity of ultrafiltration membrane fouling caused by macromolecular dissolved organic compounds in secondary effluents. Water Res. 42 (2008) 3153-3161.

[21] R.K. Henderson, R.M. Stuetz and S.J. Khan, Demonstrating ultra-filtration and reverse osmosis performance using size exclusion-chromatography. Water Sci. Technol. 62 (2010) 2747-2753.

[22] R.K. Henderson, N. Subhi, A. Antony, S.J. Khan, K. R. Murphy, G.L. Leslie, V. Chen, R.M. Stuetz and P. Le-Clech, Evaluation of effluent organic matter fouling in ultrafiltration treatment using advanced organic characterisation techniques. J. Membr. Sci. 382 (2011) 50-59.

[23] S.A. Huber, A. Balz, M. Abert and W. Pronk, Characterisation of aquatic humic and non humic matter with size-exclusion chromatography-organic carbon detection-organic nitrogen detection (LC-OCD-OND), Water Res. 45 (2011) 879-885.

[24] O. Gibert, B. Lefèvre, A. Teuler, X. Bernat and J. Tobella, Molecular weight distribution of dissolved organic matter at several stages of a conventional drinking water treatment plant. World Water Congress and Exhibition, 16-21 September 2012, Busan (Korea), International Water Association (IWA).

[25] K.J. Hwang, C.S. Chan and K.L. Tung, Effect of backwash on the performance of submerged membrane filtration, J. Membr. Sci., 330 (2009) 349-356.

[26] N.O. Yigit, G. Civelekoglu, I. Harman, H. Koseoglu and M. Kitis, Effects of various backwash scenarios on membrane fouling in a membrane bioreactor, Desalination, 237 (2009) 346-356.

[27] K.T. Chua, M.N.A. Hawlader and A. Malek, Pretreatment of seawater: Results of pilot trials in Singapore, Desalination, 159 (2003) 225-243.

[28] B.P. Espinasse, S.R. Chae, C. Marconnet, C. Coulombel, C. Mizutani, M. Djafer, V. Heim and M.R. Wiesner, Comparison of chemical cleaning reagents and characterization of foulants of nanofiltration membranes used in surface water treatment, Desalination, 296 (2012) 1-6.

[29] N. Porcelli, S. Judd, Chemical cleaning of potable water membranes: a review, Sep. Purif. Technol., 71 (2010) 137-143.

[30] C. Liu, S. Caothien, J. Hayes and T. Caothuy, Membrane chemical cleaning: from art to science. In: Proc. AWWA 2000 Water Quality Technology Conference, Denver Co.

[31] J.M. Laine, J.G. Jacangelo, N.L. Patania, J.M. Montogomery, W. Booe, J. Mallevialle and L.D. Eaux-Dumez, Evaluation of ultrafiltration membrane fouling and parameters for its control, In: Proc. AWWA 1991 Membrane Technologies in the Water Industry, Orlando Fl. 
[32] S. Strugholtz, K. Sundaramoorthy, S. Panglisch, A. Lerch, A. Brugger and R. Gimbel, Evaluation of the performance of different chemicals for cleaning capillary membranes, Desalination, 179 (2005) 191-203.

[33] S. Velten, D.R.U. Knappe, J. Traber, H.P. Kaiser, U. von Gunten, M. Boller and S. Meylan, Characterization of natural organic matter adsorption in granular activated carbon adsorbers. Water Res. 45 (2011) 3951-3959.

[34] J. Haarhoff, M. Kubare, B. Mamba, R. Krause, T. Nkambule, B. Matsebula, and J. Menge, NOM characterization and removal at six Southern African water treatment plants. Drink. Water Eng. Sci. 3 (2010) 53-61.

[35] W. Neubrand, S. Vogler, M. Ernst and M. Jekel, Lab and pilot scale investigations on membrane fouling during the ultrafiltration of surface water, Desalination 250 (2010) 968-972.

[36] N. Lee, G. Amy, J.P. Croué and H. Buisson, Identification and understanding of fouling in low-pressure membrane (MF/UF) filtration by natural organic matter (NOM), Water Res. 38 (2004) 4511-4523.

[37] J. Tian, M. Ernst, F. Cui and M. Jekel, Correlations of relevant membrane foulants with UF membrane fouling in different waters, Water Res. 47 (2013) 1218-1228.

[38] J. Haberkamp, M. Ernst, H. Paar, D. Pallischeck, G. Amy and M. Jekel, Impact of organic fractions identified by SEC and fluorescence EEM on the hydraulic reversibility of ultrafiltration membrane fouling by secondary effluents. Desalin. Water Treat. 29 (2011) 73-86.

[39] M. Peter-Varbanets, J. Margot, J. Traber and W. Pronk, Mechanisms of membrane fouling during ultra-low pressure ultrafiltration. J. Membr. Sci. 377 (2011) 42-53.

[40] D. Jermann, W. Pronk, S. Meylan and M. Boller, Interplay of different NOM fouling mechanisms during ultrafiltration for drinking water production, Water Res. 41 (2007) $1713-1722$.

[41] P.J. Smith, S. Vigneswaran, H.H. Ngo, R. Ben-Aim and H. Nguyen, A new approach to backwash initiation in membrane systems, J. Membr. Sci., 278 (2006) 381-389.

[42] Y. Bessiere, C. Guigui, P.J. Remize and C. Cabassud, Coupling air-assisted backwash and rinsing steps: a new way to improve ultrafiltration process operation for inside-out hollow fibre modules, Desalination, 240 (2009) 71-77. 